"This is the peer reviewed version of the following article: [LORENTE S., GIMENO R., LOSILLA J.M., GARZÓN S. \& VIVES J. (2018) Benefits of the humidified low-flow oxygen therapy in infants with mild-moderate bronchiolitis. Journal of Clinical Nursing, 27, 1125-1133, DOI:

10.1111/jocn.14140]. This article may be used for non-commercial purposes in accordance with Wiley Terms and Conditions for Use of Self-Archived Versions."

\title{
Benefits of the humidified low-flow oxygen therapy in infants with mild-moderate bronchiolitis
}

Sonia Lorente, Rebeca Gimeno, Josep-Maria Losilla, Sandra Garzón, Jaume Vives

Sonia Lorente, Psychologist, Pediatric Nurse, MSc (sonia.lorentes@e-campus.uab.cat) Department of Psychobiology and Methodology of Health Science, Universitat Autònoma de Barcelona, UAB; Pediatric Department, Hospital de Terrassa, Consorci Sanitari de Terrassa; Rebeca Gimeno, Pediatric Nurse, MN (rebeca4tonda@hotmail.com), and Sandra Milena Garzón, Pediatric Nurse (sandradb61@ @otmail.com), Pediatric Department, Hospital de Terrassa, Consorci Sanitari de Terrassa; Josep Maria Losilla, PhD, Statician (JosepMaria.Losilla@uab.cat) and Jaume Vives, PhD, Statician (jaume.vives@uab.cat), Department of Psychobiology and Methodology of Health Science, Universitat Autònoma de Barcelona, UAB.

This work was partially supported by the Spanish Ministry of Science and Innovation (grant number: PSI2014-52962-P). The funders had no role in the study design, data collection and analysis, decision to publish, or preparation of the manuscript. The authors declare no conflict of interest. Authors have no financial relationships relevant to this article to disclose.

We would like to sincerely thank Antonia Villalba, the Nursing Supervisor of Pediatric Department, for the financial support, Abel Martínez, the Medical Chief of Pediatric Department, for his guidance, as well as the nurses, the auxiliary staff and the doctors, for their collaboration in the collecting data process.

Correspondence concerning this article should be addressed to Sonia Lorente, Paediatric Department, Hospital de Terrassa, Consorci Sanitari de Terrassa; Department of Psychobiology and Methodology of Health Science, Universitat Autònoma de Barcelona, UAB (sonia.lorentes@e-campus.uab.cat) 


\section{ABSTRACT}

Background: There is no evidence to support the use of humidification in low-flow oxygen therapy as a usual clinical practice in the management of bronchiolitis. Aims and objectives: To investigate the clinical benefits of using humidification in low-flow oxygen therapy. Specific objectives were to investigate via an assessment of the number of nasal lavages whether humidification can help to decrease the nasal mucus viscosity, to determine whether it can relieve feeding difficulties by comparing the weight gain in infants, to ascertain whether it can relieve respiratory distress by assessing the heart and respiratory rates and contribute to improved clinical outcomes, measured by the length of stay and oxygen requirements. Design: A controlled quasi-experimental study. Methods: A total of 97 infants were included, aged $\leq 6$ months, with bronchiolitis, low-flow oxygen therapy and bronchodilators nebulized with hypertonic saline 3\%. Data from the control group (non-humidified) were gathered from 2010 2012 (49 infants), and data from the group with humidification from 2012 - 2014 (48 infants). Linear and Poisson regressions were performed adjusting for relevant characteristics of patients. Results: Humidification was shown to be associated with significant reductions in the number of nasal lavages in infants with Sant Joan de Déu Bronchiolitis Scores of BROSJOD $\leq 7$, in the heart rate of infants with mixed bronchodilators treatment, and in the length of stay and oxygen requirements of infants with Score BROSJOD $\leq 5$. No differences in weight and respiratory rate were found. Conclusions: Humidification in low-flow oxygen therapy is an effective nursing intervention to improve the clinical outcomes of infants with mild-moderate bronchiolitis.

Clinical implications: Humidifying the nasal mucosa can help to reduce the need for professional procedures, oxygen requirements and hospitalization length. Further research into the economic 
savings involved is recommended. Key words: Bronchiolitis, Humidification, Low-Flow Oxygen Therapy, Infant, Nursing 


\section{SUMMARY STATEMENT}

\section{'What does this paper contribute to the wider global clinical community?'}

- There are no prior recommendations nor any conclusive results related to the clinical benefits of humidification in low-flow oxygen therapy in infants.

- Our findings support the use of humidification in the management of mild to moderate bronchiolitis as a usual clinical practice to improve the clinical outcomes and comfort of infants. 


\section{INTRODUCTION}

Bronchiolitis is the most common lower respiratory infection in infants younger than two years of age, and it is mainly caused by the respiratory syncytial virus, RSV. The normal epidemic season for bronchiolitis lasts from December to March, and the pathology includes acute inflammation, bronchiole edema, and increased mucus production. The signs and symptoms begin with rhinitis and cough, which may progress to tachypnea, wheezing, rales, use of accessory muscles and/or nasal flaring (American Academy of Pediatrics, 2014). The maintenance of hydration and oxygenation, as a supportive treatment, is generally recommended to manage acute bronchiolitis, since different trials of other treatments such as corticosteroids or antibiotics have not demonstrated conclusive benefits (American Academy of Pediatrics, 2014; Krilov, 2011).

\section{Background}

With regard to oxygenation management, noninvasive ventilation is commonly implemented during hospitalization, in the form of either high-flow (HF) oxygen therapy or lowflow (LF) oxygen therapy. When the HF system is implemented, the humidification of oxygen is a usual clinical practice, undertaken in order to prevent some complications of dry oxygen delivery, including nasal dryness and discomfort (Cuquemelle et al., 2012). However, despite the complications of the dry oxygen conditioning, there is neither a widespread consensus nor any standard recommendations about the use of humidified oxygen in LF rates.

On the one hand, some hospital guidelines always recommend the humidification of oxygen in infants, regardless of the flow rates, as the Saskatoon Health Region Nursing Practice 
Committee policies (2006). On the other hand, Nath, Ponnusany, Willis, Bisset, \& Clarke (2010), reported a wide variety of clinical practices in the neonatal care with regard to humidification measures in LF therapy, thus complicating any effort to define standard policies, as stated above. Lastly, Umoren, Odey, \& Meremikwu (2011) concluded that there have not been enough welldesigned trials to examine the benefits of humidified oxygen in the treatment of acute bronchiolitis in children of up to three years of age. Because of this lack of evidence and consensus, both Nath et al. (2010) and Umoren, Odey, \& Meremikwu (2011), recommend further research to explore the effectiveness of humidified vs. non-humidified oxygen therapy. In addition, the humidification may be helpful to prevent the thickening of secretions (Walsh \& Smallwood, 2017) and relieving the main symptoms of respiratory distress. Finally, no adverse effects have been reported, either with steam humidification (Umoren, Odey, \& Meremikwu, 2011), or by using prefilled bubble humidifiers (Yamashita, Nishiyama, Yokoyama, Abe, \& Manabe, 2005), and only benefits may be expected.

Thus, given this call for an examination of the benefits of humidified oxygen in lowflow therapy, the humidification of oxygen in LF was implemented as a general practice in the management of all infants with bronchiolitis in our paediatric ward, and we compared its effects to non-humidified oxygen therapy. The overall objective was to investigate the clinical benefits of using humidification as a usual clinical practice in low-flow oxygen therapy in the management of infants with acute bronchiolitis. Our specific hypotheses were that the use of the humidification in low-flow oxygen therapy in infants with mild-moderate bronchiolitis would reduce their nasal mucus viscosity, thus alleviating the infants' feeding difficulties and easing their respiratory distress, and that it would improve their clinical outcomes. 


\section{METHODOLOGY}

\section{Design, setting and participants}

A quasi-experimental study with a non-concurrent control group was conducted at our general pediatric ward, in a Spanish non-tertiary hospital. A total of 97 infants with mildmoderate bronchiolitis with low-flow oxygen therapy, defined as $\leq 2 \mathrm{~L} / \mathrm{min}$, administered via nasal cannula, were enrolled. The control (non-humidified) group data were gathered during the annual RSV incidence peak from November to March of the years 2010 to 2012, and consisted of observations of 49 infants. The study group (humidified) data were collected in the same seasonal period, 2012-2014, with this group consisting of 48 infants. The prevalence of RSV in the groups was between $70 \%-83 \%$, similar to the reference population with bronchiolitis in Spain (Flores-González et al., 2017).

We included all infants younger than six months old, with diagnoses of bronchiolitis based on an initial episode of respiratory distress, with LF oxygen therapy, and bronchodilators (salbutamol and/or epinephrine), nebulized with hypertonic saline 3\%. We excluded infants with previous respiratory tract infections and co-infections at admission (pneumonia, bordetella pertussis, tract urinary infection), and infants with risk factors for severe disease, such as chronic diseases (congenital heart disease, chronic lung disease, immunodeficiency, neuromuscular diseases) and premature birth (American Academy of Pediatrics, 2014; Krilov, 2011). Those infants who needed different management due to co-infections detected during the bronchiolitis treatment, as well as those who ultimately needed to be admitted in the pediatric intensive care unit (PICU), were also excluded (Figure 1). 
-Insert Figure 1 here o near here-

\section{Study variables}

To evaluate the degree to which humidification can contribute to a decrease in nasal mucus viscosity, the number of nasal lavages needed to alleviate the nasal obstruction was recorded as an indirect indicator. To assess feeding difficulties, data were gathered on the infants' weight gain, with each infant's weight in grams recorded at admission and at discharge, in each case with the baby naked and weighed on the same digital scale both times. In order to evaluate respiratory distress, measurements were taken of the infants' respiratory rate (RR) (counted by professionals during one minute) and of their heart rate (HR) and oxygen saturation (SpO2) (measured with pulse-oximetry) at admission and then after 24, 48, and 72 hours, and again at discharge. The distress score was also recorded at admission by using the Sant Joan de Déu Bronchiolitis Score (BROSJOD) (Balaguer et al., 2017). The bronchodilator therapy was recorded, because the use of epinephrine rather than salbutamol may be slightly more effective (Modaressi, Asadian, \& Faghihinia, 2012). To assess the length of stay (LoS), we defined the period of days between the admission in our ward and the validation of the discharge criteria, generally when the oral fluid intake was adequate, the SpO2 was >95\% without oxygen supply for at least twenty-four hours, and the infant exhibited minimal wheezes, rales, and chest retractions. To measure the length of oxygen requirement (LOR) we recorded the period of days necessary to decrease the work of breathing to the minimum with the supply of oxygen. 


\section{Potential confounders}

Some potential confounders were controlled for this study; the infants' age, because the most severe bronchiolitis episodes are associated with infants aged less than 12 weeks (American Academy of Pediatrics, 2014); the infants' feeding (categories: breastfeeding, formula or mixed), since exclusive breastfeeding may have protective effects on infectious diseases, as bronchiolitis (American Academy of Pediatrics, 2014; Duijts, Jaddoe, Hofman, \& Moll, 2010); the use of antibiotic agents (categories: presence or absence), given that despite the lack of evidence of their benefits in treating this viral infection (American Academy of Pediatrics, 2014), the administering of antibiotics might relieve some symptomatology; the findings in radiography and RSV diagnoses (García et al., 2010) (categories: presence or absence), since both variables may lead to worsened outcomes. Finally, pre-natal maternal smoking and the household smoking exposure were also recorded (categories: yes or no), because household tobacco exposure may increase clinical severity in bronchiolitis (Semple, Taylor-Robinson, Lane, \& Smyth, 2011)

\section{Procedure}

The choices of management practices for infants with bronchiolitis at our hospital always depend on each infant's clinical status. These interventions range from the maintenance of oxygenation through the use of LF when the bronchiolitis episode is mild or moderate and the $\mathrm{SpO} 2<94 \%$, to the maintenance of hydration by encouraging the oral fluid intake in infants diagnosed with a mild-moderate episode, and to the prescription of intravenous fluids or tube feeding, only in very exceptional and critical situations. They also include the administration of bronchodilators by nebulizing salbutamol and/or epinephrine with $3 \%$ hypertonic saline and 
antibiotic therapy. In addition, the nasal lavages are also recommended to alleviate the nasal obstruction due to mucus viscosity. This practice consists of the instillation of $2 \mathrm{cc}$ to $5 \mathrm{cc}$ of normal saline into the infant's nostrils, a process that is much less aggressive than nasal suctioning, although it still causes discomfort. Thus, to reduce the discomfort of infants associated to nasal lavages, we implemented the humidification in infants with bronchiolitis and LF oxygen therapy using the bubble sterile device Respiflo@, Tyco Healthcare (Tyco Healthcare Group, 2004a), which has been available in our pediatric ward since November 2012.

The general procedure during this study was to administer humidification to all infants with bronchiolitis who needed LF oxygen therapy, and at the time of admission to register the distress score as measured by the Sant Joan de Déu Bronchiolitis Score (BROSJOD) (Balaguer et al., 2017), as well as each infant's vital signs, weight, and potential confounding variables. The patients were monitored during their stay, with records taken of their vital signs, and weight at discharge. Infants with co-infections and complications were excluded from the study, as mentioned above (Figure 1). Because this practice was implemented as a usual prescription, a concurrent group without humidification was not possible.

\section{Data collection}

Data from the from the control, non-humidified group (2010-2012) were collected via a review of medical records, and data from the humidified group (2012-2014) were gathered using a specific form, designed for the purposes of this study. Demographic data from both groups were also recorded. 


\section{Instruments}

\section{Respiflo@ cold bubble device}

This is a closed system with a special adapter, suitable for the administration of humidified respiratory gases or/and nebulized therapy. The closed system and the adapters reduce the risk of contamination associated with other conventional open systems. This device is suitable for the conditioning of dry respiratory gases in short-term low-flow oxygen therapy administered with nasal cannulas (Tyco Healthcare Group, 2004; Yamashita et al., 2005)

\section{Sant Joan de Déu Bronchiolitis Score (BROSJOD)}

The Sant Joan de Déu Bronchiolitis Score (BROSJOD score) was originally developed in 1999 (Caritg et al. 1999, cited in Balaguer et al. 2017), and it was recently validated as a diagnostic severity tool in infants aged less than two years, mean age 52.5 days, admitted to Hospital Sant Joan de Déu with acute bronchiolitis (Emergency Department, ward, or PICU) (Balaguer et al. 2017). At admission, the BROSJOD showed good internal consistency (Cronbach's alpha 0.75 [95\% CI 0.71-0.82]), high inter-rater reliability (Concordance Correlation Coefficient, CCC 0.96 [95\% CI 0.94-0.97]), and good discriminative validity (Volume Under Surface, VUS 0.80 [95\% CI 0.70-0.90]). This score was specifically developed to address the severity of bronchiolitis in children, while other measures as the Wood-Downes (WD) scale were adapted from asthma scores and modified for younger children. In addition, the BROSJOD score considers RR and HR classified according to the age of infants, and it measures data not only on cyanosis but also on oxygen saturation, using pulse-oximetry. Severity score values ranged from 1 to 16 . Higher scores indicate a more serious condition, with cases classified 
as mild crises (values 0 to 5), moderate crises (values 6 to 10) or severe crises (values 11 to 16) (Balaguer et al. 2017) (Table 1).

Insert Table 1 here or near here

\section{Ethical aspects}

This study was conducted according to the principles expressed in the Declaration of Helsinki of 1975, revised in 1983, and was approved by the Hospital de Terrassa Ethics Committee (CEIC, Comité de Ética e Investigación Clínica). The parents’ oral consent was obtained, and the data were gathered anonymously. Non-adverse effects were reported by professionals and parents.

\section{Analysis}

Linear and Poisson regressions were performed to investigate the impact of the use of humidification in low-flow oxygen therapy in infants with mild-moderate bronchiolitis, adjusting for the patients' relevant characteristics. Furthermore, we tested the interaction of humidification with the BROSJOD score to assess whether the impact of humidification on the number of nasal lavages, the length of stay (LoS) and the length of oxygen requirement (LOR) was the same at different severity levels of bronchiolitis. We also tested the interaction of humidification with the type of bronchodilator treatment used in order to assess the impact of humidification on heart rate $(\mathrm{HR})$ and respiratory rate $(\mathrm{RR})$. Regression backward model selection was conducted, fitted using IBM SPSS Statistics v19.0 package (IBM Corp, 2011). The results of the association between treatment (humidification/no humidification) and each response investigated are presented as non-linear Poisson regression coefficients $(\operatorname{Exp}(B))$ for count responses, and as 
linear regression coefficients (B) for quantitative responses, reporting 95\% confidence intervals (95\% CI), and P-values (P) in both cases.

\section{RESULTS}

\section{Demographic characteristics and descriptive statistics of study variables}

Table 2 shows the infants' clinical and demographic characteristics. Our groups were comparable in age, admission weight, BROSJOD scores, RSV diagnoses, antibiotic therapy, radiography findings and family smoking habits. However, the groups showed differences in terms of feeding and bronchodilator treatment, so these variables were adjusted in the statistical analysis, in regression models. Concerning the group characteristics, $71 \%$ of infants in the control group (non-humidified) and $83 \%$ in the humidified group were diagnosed as RSV positive, while most subjects had mild to moderate bronchiolitis scores, were of less than ninety days of age and had been exclusively breastfed. Table 3 shows the descriptive statistics and the results of the bivariate comparisons for each study variable.

-Insert Table 2 here or near here

Insert Table 3 here or near here-

\section{Effects of humidification}

In order to analyze the effect of humidification on the number of nasal lavages, a Poisson regression model was tested. This model included the interaction of humidification with the BROSJOD score adjusting for breastfeeding and age. Table 4 shows the results of the final model, where only the interaction of humidification with the BROSJOD score was kept. The 
humidified group showed a significant reduction in the number of nasal lavages. As the score decreases, the number of nasal lavages is also reduced, with some cases showing a reduction by as much as $78.5 \%($ Score BROSJOD $=3)$

-Insert Table 4 here or near here

Concerning feeding difficulties, the infants' weight gain during the stay was analyzed using a linear regression model adjusted for age, but no significant differences were found $(\mathrm{B}=-$ 2.456 grams [95\% CI: $-64.5-59.6], \mathrm{p}=0.938)$.

To analyze the effect of humidification on respiratory distress, linear regression models were tested, with the HR and RR as response variables. This model included the interaction of humidification with the BROSJOD score and adjusted for bronchodilators and age. Table 5 shows the results of the final model, where only the interaction of humidification with bronchodilators remains. Infants with humidification and mixed bronchodilators treatment (salbutamol and epinephrine) showed a reduction in HR (B=-11.49 beats [95\% CI: -19.68 - 3.30], $\mathrm{p}=0.06)$. No significant differences in respiratory rates were observed. -Insert Table 5 here or near here-

To analyze the effect of humidification on clinical outcomes, Poisson regression models were applied, with LoS and LOR as response variables. These models also included the interaction of humidification with the BROSJOD score and were adjusted for admission weight, breastfeeding and age. Table 6 shows the final model, where only the interaction of humidification with the BROSJOD score was kept. As this score decreases, there is a 
corresponding reduction in the LoS and LOR, with the values for the latter two variables decreasing by as much as $58.2 \%$ and $69.5 \%$, respectively (BROSJOD score $=3$ )

Insert Table 6 here or near here-

\section{DISCUSSION}

Bronchiolitis is an active area of research. Ninety percent of infants are infected with RSV in the first two years of life, and the treatment of this virus comes with a huge health care cost (American Academy of Pediatrics, 2014). For this reason, numerous reviews are constantly being conducted in order to improve the management of these infants (Øymar, Skjerven, \& Mikalsen, 2014; Schroeder \& Mansbach, 2014; Zentz, 2011). In this sense, the use of humidification in HF rates is almost an unquestionable clinical practice that helps enhance infants' comfort levels (Cuquemelle et al., 2012) and reduce the risk of complications (Dysart, Miller, Wolfson, \& Shaffer, 2009). However, as mentioned previously, there are discrepancies in the research on the use of humidification in LF, because to date there is no conclusive evidence of its benefits (Nath et al., 2010; Umoren et al., 2011). To our knowledge, this is the first study reporting clinical benefits of the use of humidification in LF oxygen therapy in mild-moderate bronchiolitis.

\section{Number of nasal lavages}

Humidification seems to be helpful in reducing the number of nasal lavages needed to alleviate the nasal obstruction. The data confirm our hypothesis, since the humidification in LF may lighten secretions, as Umoren et al. (2011) suggested. In addition, reducing the number of nasal lavages may minimize the impact of nursing procedures. This "minimal handling" 
approach may be especially beneficial in infants aged less than three months, as Øymar et al. (2014) suggested. As expected, the effect of the humidification in LF decreased the number of nasal lavages in infants with lower BROSJOD scores, since infants scoring higher may need other supportive measures, such as heated humidification.

\section{Feeding difficulties}

The difference in weight gain was not statistically significant. These results, however, could have been significantly different if we had measured and analyzed their weight daily to examine the fluctuations. In addition, we could have examined how well the infant was feeding (i.e., how long it takes to complete a feed, and if the infant is breastfeeding, enquire as to whether the mother feels that her breast is being emptied), as Fitzgerald \& Kilham (2004) recommended as ways to assess the clinical severity of bronchiolitis episodes.

\section{Respiratory distress}

Humidification decreased the mean HR significantly, and no statistical differences in the RR were found. These findings partially confirm our hypothesis, since decreasing the thickness of secretions may relieve respiratory distress, as was pointed out by Umoren et al. (2011). HR is considered a distress indicator in some instruments assessing bronchiolitis severity, including the BROSJOD score and other generally accepted measures like the WoodDownes Clinical Scoring System, modified by Ferrés (Flores-González et al., 2016). When these instruments are used, lower HR generally contributes to lower scores and thus to decreased severity and improvements in infants' clinical evolution. The RR slightly decreased, but results were statistically not significant. This fact may be due to the measuring system used, because whereas the HR was measured with a pulse oxymeter, which brings valid and reliable data, RR 
was measured by professionals, who gathered this data by counting. In this sense, the recording of RR may vary from one professional to another, and so the analysis may be altered. So, no conclusive results were found concerning $\mathrm{RR}$, but our results regarding the redution of HR were statistically significant and may be helpful for future research.

\section{Length of stay and length of oxygen requirement}

Humidification significantly reduced the LoS and the LOR. These results confirm our hypothesis, since lightening secretions and relieving respiratory distress seem to improve infants' clinical outcomes. This effect was associated with lower BROSJOD scores, as well as with reduction in the number of nasal lavages required, both these results likely owing to the same explanation. Apart from the relationship of humidification with the BROSJOD score, no other associations were found, although we initially expected an association between length of stay and breastfeeding. The lack of association between these two variables could be explained by the fact that most of the infants in our groups were of less than ninety days of age, whereas the contribution of exclusive breastfeeding to improve outcomes in respiratory tract infections, including reductions in the length of stay, has been described for infants who have been exclusively breastfed for at least four months (American Academy of Pediatrics, 2014; Duijts et al., 2010)

\section{Limitations}

Some limitations should be noted and taken into account for further research. Our design did not include a concurrent control group without humidification, because this system was implemented as a general practice at our ward. While this non-experimental design does not ensure the comparability between groups, differences detected between groups regarding 
potential confounders were controlled for using regression models, as mentioned in the results section. We did not have a control group without bronchodilator treatment because our clinicians administer bronchodilators as a general rule, as detailed in the procedure section. We recorded the clinical distress score at admission to determine the severity of the bronchiolitis episode, but we did not register the score evolution during the stay. We did not quantitatively register the oral fluid intake of infants during the study, so we could not control for their hydration status as would have been desirable. Finally, we could not analyze the interaction of humidification with BROSJOD scores over 8, due to the insufficient number of infants in the humidified group.

\section{Implications for clinical practice and further research}

Humidification in LF may be an effective nursing intervention to improve the management of infants with mild-moderate bronchiolitis, reducing the discomfort associated with the dry oxygen delivery and nursing handling, relieving respiratory distress and improving

clinical outcomes. Thus, humidification in low-flow oxygen therapy should be recommended as a regular clinical practice, since this viral infection is widespread and highly prevalent. In addition, our results may be generalizable to other clinical scenarios in Spain where the management of infants with bronchiolitis is very similar, such as in bronchodilators nebulized with 3\% hypertonic saline and when antibiotics are also prescribed (Flores-González et al., 2016, 2017). In other countries, clinicians also prescribe antibiotics, bronchodilators and corticosteroids, with examples found in Italy (De Brasi et al., 2010) or Finland (Elenius et al., 2017), despite the fact that administering these treatments has not been shown to have conclusive benefits (American Academy of Pediatrics, 2014). Along the same lines, and although nasal suctioning is not routinely recommended by the American Academy of Pediatrics guidelines 
(2014), other protocols and guidelines have highlighted the relevance of suctioning nasal secretions before any inhaled therapy application or prior to feeding (Black \& Brennan, 2011; Cincinnati Children's Hospital Medical Center, 2006). In these cases, we usually do nasal lavages, which are much less aggressive than nasal suctioning.

Moreover, some others issues concerning the economic costs should also be highlighted. Regarding the humidification system implementation, the bubble device in our public hospital costs less than one euro per infant/week, whereas a one-day stay costs nearly 300 euros. Although the costs may vary depending on the device brand used and the clinical scenario, the humidification system still remains economical (Villanueva \& Bayón, 2013). Additionally, other cost savings should be taken into account if the humidification in LF is implemented, including the cost-time of the nursing procedures and the medical costs resulting from the possible complications of dry oxygen delivery. In this sense, further research is needed, because in this study we did undertake an analysis of the cost-effectiveness of humidification in LF. We also recommend conducting prospective studies with a control group to clarify the role of bronchodilators in association with the humidification, registering the exact dose-frequency of epinephrine and salbutamol. Finally, to follow infants' clinical evolution more accurately, we strongly recommend registering distress scores daily, because this measure seems to be a good predictor of clinical outcomes, as highlighted by Balaguer et al. (2017)

\section{CONCLUSION}

The use of humidification in LF oxygen therapy seems to be clinically beneficial. Humidifying the nasal and oral mucosa can help to lighten secretions, reduce the number of nasal lavages and minimize infants' discomfort associated with mucosa dryness, nasal obstruction and 
professional procedures. Humidification also relieves respiratory distress and reduces the LoS and the LOR. Our findings support the use of humidification in LF as a regular clinical practice in the management of mild-moderate bronchiolitis. 


\section{References}

American Academy of Pediatrics. (2014). Clinical Practice Guideline: The Diagnosis, Management, and Prevention of Bronchiolitis 2014. Pediatrics, 134, e1474-e1502. http://doi.org/10.1542/peds.2014-2742

Balaguer, M., Alejandre, C., Vila, D., Esteban, E., Carrasco, J. L., Cambra, F. J., \& Jordan, I. (2017). Bronchiolitis Score of Sant Joan de Déu: BROSJOD Score, validation and usefulness. Pediatric Pulmonology, 52, 533-539. http://doi.org/10.1002/ppul.23546

Black, A., \& Brennan, R. A. (2011). Breathing Easy: Implementing A Bronchiolitis Protocol. Pediatric Nursing, 37(3), 129-135.

Cincinnati Children’s Hospital Medical Center. (2006). Evidence based clinical practice guideline for medical management of bronchiolitis in infants less than 1 year of age presenting with a first time episode. Cincinnati Children's Hospital Medical Center, 1-13.

Cuquemelle, E., Pham, T., Papon, J.-F., Louis, B., Danin, P.-E., \& Brochard, L. (2012). Heated and Humidified High-Flow Oxygen Therapy Reduces Discomfort During Hypoxemic Respiratory Failure. Respiratory Care, 57(10), 1571-1577. http://doi.org/10.4187/respcare.01681

De Brasi, D., Pannuti, F., Antonelli, F., de Seta, F., Siani, P., \& de Seta, L. (2010). Therapeutic approach to bronchiolitis: why pediatricians continue to overprescribe drugs? Italian Journal of Pediatrics, 36, 1-8. http://doi.org/10.1186/1824-7288-36-67

Duijts, L., Jaddoe, V. W. V, Hofman, A., \& Moll, H. A. (2010). Prolonged and exclusive breastfeeding reduces the risk of infectious diseases in infancy. Pediatrics, 126(1), e18-25. 
http://doi.org/10.1542/peds.2008-3256

Dysart, K., Miller, T. L., Wolfson, M. R., \& Shaffer, T. H. (2009). Research in high flow therapy: Mechanisms of action. Respiratory Medicine, 103(10), 1400-1405. http://doi.org/10.1016/j.rmed.2009.04.007

Elenius, V., Bergroth, E., Koponen, P., Remes, S., Piedra, P. A., Espinola, J. A., ... Jartti, T. (2017). Marked variability observed in inpatient management of bronchiolitis in three Finnish hospitals. Acta Paediatrica, 1-7. http://doi.org/10.1111/apa.13931

Fitzgerald, D. A., \& Kilham, H. A. (2004). Bronchiolitis: Assessment and evidence-based management. Medical Journal of Australia, 180(8), 399-404.

Flores-González, J. C., Mayordomo-Colunga, J., Jordan, I., Miras-Veiga, A., MonteroValladares, C., Olmedilla-Jodar, M., ... Goñi-Orayen, C. (2017). Prospective Multicentre Study on the Epidemiology and Current Therapeutic Management of Severe Bronchiolitis in Spain. Biomed Research International, 2017. http://doi.org/10.1155/2017/2565397

Flores-González, J. C., Rodríguez-Campoy, P., Pérez-Guerrero, J., Serrano-Moyano, B., PalmaZambrana, E., Comino-Vázquez, P., ... Flores González, J. C. (2016). Effect of Nebulized 3\% Hypertonic Saline on Intensive Care Unit Admission Rates of Infants with Moderate Acute Bronchiolitis. Journal of Clinical Research \& Bioethics, 7(4), 3-7. http://doi.org/10.4172/2155-9627.1000281

García, C. G., Bhore, R., Soriano-Fallas, A., Trost, M., Chason, R., Ramilo, O., \& Mejias, A. (2010). Risk factors in children hospitalized with RSV bronchiolitis versus non-RSV bronchiolitis. Pediatrics, 126(6), e1453-60. http://doi.org/10.1542/peds.2010-0507 
Krilov, L. R. (2011). Respiratory syncytial virus disease: update on treatment and prevention. Expert Review of Anti-Infective Therapy, 9(1), 27-32. http://doi.org/10.1586/eri.10.140

Modaressi, M., Asadian, A., \& Faghihinia, J. (2012). Comparison of Epinephrine to Salbutamol in Acute Bronchiolitis. Iranian Journal of Pediatrics, 22(2), 241-244.

Nath, P., Ponnusany, V., Willis, K., Bisset, L., \& Clarke, P. (2010). Current practices of high and low flow oxygen therapy and humidification in UK neonatal units. Pediatrics International, 52(6), 893-4. http://doi.org/10.1111/j.1442-200X.2010.03274.X

Øymar, K., Skjerven, H. O., \& Mikalsen, I. B. (2014). Acute bronchiolitis in infants , a review. Scandinavian Journal of Trauma, Ressucitation and Emergency Medicine, 22(1), 23. http://doi.org/10.1186/1757-7241-22-23

Saskatoon Health Region Nursing Practice Committee. (2006). Oxygen Administration Policies \& Procedures. Retrieved from https://www.saskatoonhealthregion.ca/about/NursingManual/1115.pdf

Schroeder, A. R., \& Mansbach, J. M. (2014). Recent evidence on the management of bronchiolitis. Current Opinion in Pediatrics, 26(3), 328-333. http://doi.org/10.1097/MOP.0000000000000090

Semple, M. G., Taylor-Robinson, D. C., Lane, S., \& Smyth, R. L. (2011). Household tobacco smoke and admission weight predict severe bronchiolitis in infants independent of deprivation: prospective cohort study. PloS One, 6(7), e22425. http://doi.org/10.1371/journal.pone.0022425 
Tyco Healthcare Group. (2004). Humidification Nebulisation Oxygen Therapy. What is Respiflo? Retrieved from http://www.gulcanlarmedikal.com.tr/pdf/coviden/Oxygen Therapy.pdf

Umoren, R., Odey, F., \& Meremikwu, M. M. (2011). Steam inhalation or humidified oxygen for acute bronchiolitis in children up to three years of age ( Review ). Cochrane Database of Systematic Reviews, (1), 1-33. http://doi.org/10.1002/14651858.CD006435.pub2.

Villanueva, G., \& Bayón, J. (2013). Evaluation of bubble humidification systems in low-flow oxygen therapy. Systematic review and cost analysis. Ministerio de Sanidad, Servicios Sociales E Igualdad. Servicio de Evaluación de Tecnologías Sanitarias Del País Vasco. Informes de Evaluación de Tecnologías Sanitarias. Osteba (Abstract in English)

Walsh, B. K., \& Smallwood, C. D. (2017). Pediatric Oxygen Therapy: A Review and Update. Respiratory Care, 62(6), 645-661. http://doi.org/10.4187/respcare.05245

Yamashita, K., Nishiyama, T., Yokoyama, T., Abe, H., \& Manabe, M. (2005). A comparison of the rate of bacterial contamination for prefilled disposable and reusable oxygen humidifiers. Journal of Critical Care, 20(2), 172-175. http://doi.org/10.1016/j.jcrc.2005.01.002

Zentz, S. E. (2011). Care of infants and children with bronchiolitis: a systematic review. Journal of Pediatric Nursing, 26(6), 519-29. http://doi.org/10.1016/j.pedn.2010.07.008 


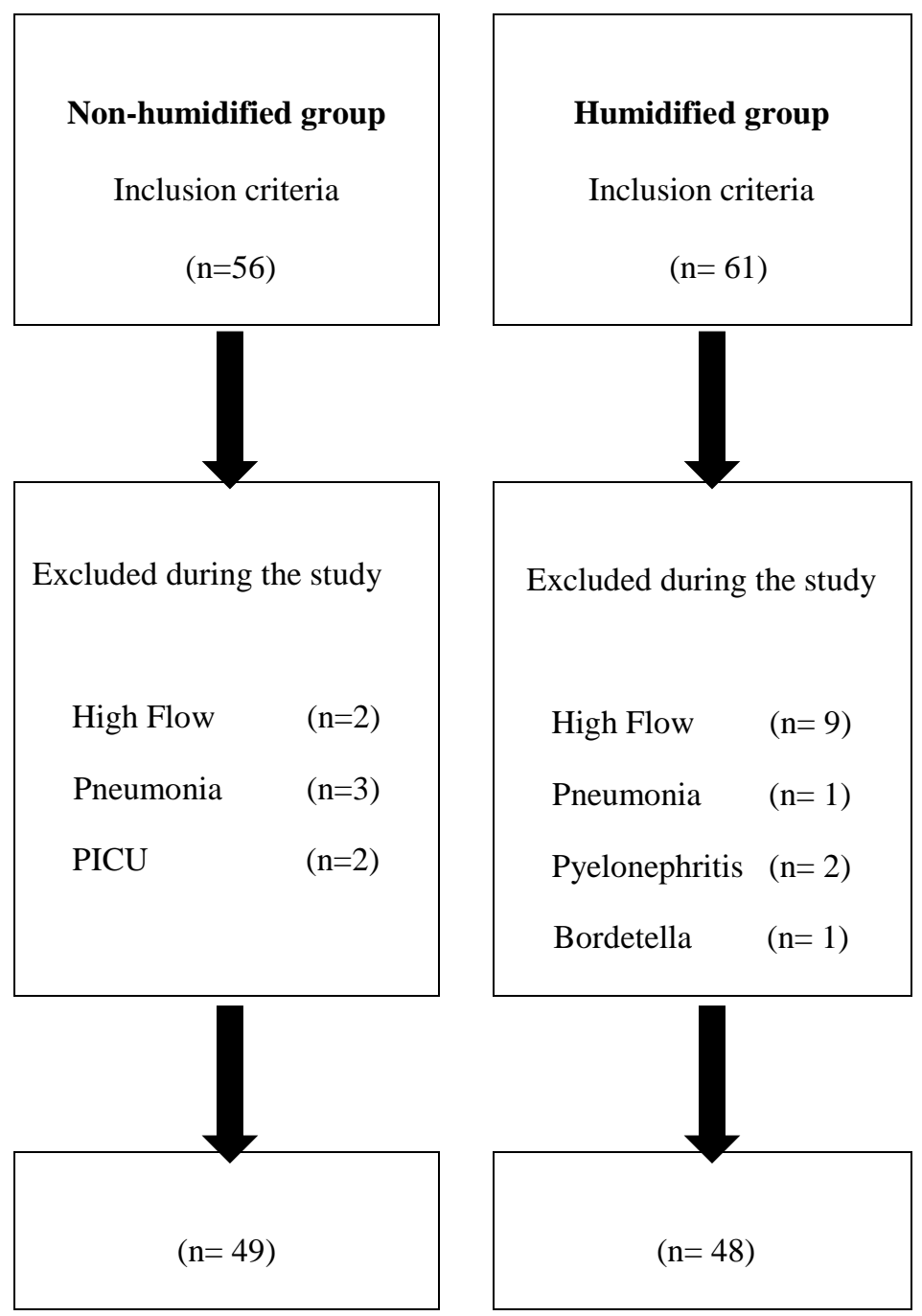

Figure 1 Flow diagram of selection of study patients 
Table 1 Bronchiolitis Score of San Joan de Déu, BROSJOD (Balaguer et al., 2017)

\begin{tabular}{llll}
\hline Wheezing/rales & 0 & No \\
1 & Expiratory wheezes /Inspiratory rales \\
& 2 & Expiratory and Inspiratory wheezes/rales \\
\hline Indrawing & 0 & No \\
1 & Subcostal + lower intercostal \\
2 & Previous + supraclavicular + nasal flaring \\
& 3 & Previous + upper intercostal + tracheal tug \\
\hline Air entry & 0 & Normal \\
1 & Regular and symmetric \\
2 & Asymmetric \\
3 & Very reduced
\end{tabular}

Oxygen saturation

With oxygen Without oxygen

$0 \quad \geq 95 \% \quad \geq 95 \%$

$1 \quad 91-94 \% \quad>94 \%$ with $\mathrm{FIO}_{2} \leq 40 \%$

$2 \leq 90 \% \quad \leq 94 \%$ with $\mathrm{FIO}_{2} \leq 40 \%$

Respiratory Rate (rpm)

0

$<3$ months

3-12 months

12-24 months

$<30 x^{\prime}$

$<40 x^{\prime}$

$<30 x^{\prime}$

$-49 x$

30-39x'

1

130-149/x'

$110-120 / x^{\prime}$
$<130 / x^{\prime}$

$<110 / x^{\prime}$
1

40-59x'

$<1$ year

1-2 years

$$
<110 / x^{\prime}
$$

60-70x'

50-60x'

$40-50 x^{\prime}$

2

3

$150-170 / x^{\prime}$

120-140/x'

$>170 / x^{\prime}$

$>140 / x^{\prime}$

Note: Fraction of inspired oxygen $\left(\mathrm{FIO}_{2}\right)$; respirations per minute (rpm); beats per minute (bpm); Overall Score ranked into Minor crisis (0-5), Moderate crisis (6-10) and Severe crisis (11-16) 
Table 2 Demographic and clinical characteristics of infants

\begin{tabular}{|c|c|c|c|}
\hline & $\begin{array}{l}\text { Non-humidified } \\
\qquad(\mathrm{n}=49)\end{array}$ & $\begin{array}{l}\text { Humidified } \\
\qquad(\mathrm{n}=48)\end{array}$ & \\
\hline & $\%(n)$ & $\%(\mathrm{n})$ & $\mathrm{P}$ \\
\hline Age & & & 0.768 \\
\hline$<90$ days & $78(38)$ & $75(36)$ & \\
\hline$>90$ days & $22(11)$ & $25(12)$ & \\
\hline Feeding & & & 0.046 \\
\hline Breastfeeding & $59(29)$ & $73(35)$ & \\
\hline Formula & $16(8)$ & $21(10)$ & \\
\hline Mixed & $26(12)$ & $6(3)$ & \\
\hline Admission weight (grams) & & & 0.641 \\
\hline $2500-3000$ & $2(1)$ & $0(0)$ & \\
\hline $3001-3500$ & $6(3)$ & $10(5)$ & \\
\hline $3500-4000$ & $14(7)$ & $17(8)$ & \\
\hline$>4001$ & $78(38)$ & $73(35)$ & \\
\hline Smoking pregnant & & & 0.090 \\
\hline yes & $23(10)$ & $9(4)$ & \\
\hline no & $77(34)$ & $91(39)$ & \\
\hline Smoking household & & & 0.458 \\
\hline yes & $31(11)$ & $40(17)$ & \\
\hline no & $69(24)$ & $60(26)$ & \\
\hline
\end{tabular}

Note: Pearson Chi-squared test to compare groups. Sample (n); p-values (P). Data are missing on smoking pregnant (n=10, $10.3 \%)$ and smoking household $(n=19,19.6 \%)$ 
Table 3. Descriptive statistics of study variables

\begin{tabular}{|c|c|c|c|c|c|}
\hline & & No Humidifies & & Humidified & \\
\hline & $\mathrm{n}$ & $\mathrm{M} \pm \mathrm{Sd}$ & $\mathrm{n}$ & $\mathrm{M} \pm \mathrm{Sd}$ & $\mathrm{P}$ \\
\hline \multicolumn{6}{|c|}{ Weight gain (grams) } \\
\hline & 49 & $0.20 \pm 154.9$ & 48 & $13.5 \pm 139.6$ & .657 \\
\hline \multicolumn{6}{|c|}{ HR (bpm) } \\
\hline HR 24h & 49 & $147.8 \pm 16.7$ & 48 & $145.1 \pm 14.7$ & .406 \\
\hline HR 48h & 49 & $145.5 \pm 17.3$ & 48 & $139.2 \pm 15.1$ & .063 \\
\hline HR $72 \mathrm{~h}$ & 47 & $140.9 \pm 15.6$ & 47 & $138.7 \pm 13.3$ & .465 \\
\hline \multicolumn{6}{|c|}{$\mathrm{RR}(\mathrm{rpm})$} \\
\hline RR 24h & 49 & $44.0 \pm 6.6$ & 48 & $44.1 \pm 8.5$ & .852 \\
\hline RR 48h & 49 & $44.2 \pm 7.5$ & 48 & $43.0 \pm 8.7$ & .405 \\
\hline \multirow[t]{2}{*}{ RR 72h } & 47 & $41.1 \pm 6.5$ & 47 & $42.5 \pm 7.2$ & .336 \\
\hline & $\mathrm{n}$ & Md (IQR) & $\mathrm{n}$ & Md (IQR) & \\
\hline Nasal la & & & & & \\
\hline & 49 & $3(2-9)$ & 48 & $3(1-5)$ & .467 \\
\hline
\end{tabular}

Length of Stay and length of oxygen requirement

$\begin{array}{lccccr}\text { LoS } & 49 & 5(4-7) & 48 & 5(4-6) & .467 \\ \text { LOR } & 49 & 3(2-5) & 48 & 3(2-4) & .174\end{array}$

Note: Sample (n), mean (M), Standard deviation (Sd), median (Md), Interquartile Range (IQR), P-value (P), Heart rate (HR), respiratory rate $(\mathrm{RR})$, beats per minute (bpm), respirations per minute (rpm). 
Table 4 Effects of humidification on number of nasal lavages due to lightening secretions across different bronchiolitis severity Score BROSJOD levels

$$
\operatorname{ExpB}(95 \% \mathrm{CI}) \quad(\operatorname{ExpB}-1) * 100 \quad \mathrm{P}
$$

Humidification (Yes)

Score $3 \quad(n=4)$

Score $4 \quad(n=11)$

Score $5 \quad(n=18)$

Score $6 \quad(n=24)$

Score $7 \quad(n=19)$

Score $8 \quad(n=13)$
$.341(.215-.539)$

$.406(.286-.577)$

$.485(.375-.627)$

$.579(.473-.708)$

$.691(.557-.855)$

$.824(.619-1.09)$
$-65.9 \%(-78.5 \%--46.1 \%) \quad<.001$

$-59.4 \%(-71.4 \%--42.3 \%) \quad<.001$

$-55.1 \%(-62.5 \%--37.3 \%)<.001$

$-42.1 \%(-52.7 \%--29.2 \%)<.001$

$-30.9 \%(-44.3 \%--14.5 \%)<.001$

$-17.6 \%(-38.1 \%-9.8 \%) \quad .186$

Note: Poisson regression coefficients (Exp. (B)), 95\% Confidence Intervals (95\% CI), p-values (P), sample (n).

$($ ExpB - 1) * 100 shows the effect of humidification on the number of nasal lavages expressed in percentage of change. The initial model included the interaction of humidification with Score BROSJOD, and age and breastfeeding as potentials confounders, but only the interaction with Score BROSJOD was kept in the final model.

Table 5 Effects of humidification on heart rate and respiratory rate in the different bronchodilator treatments

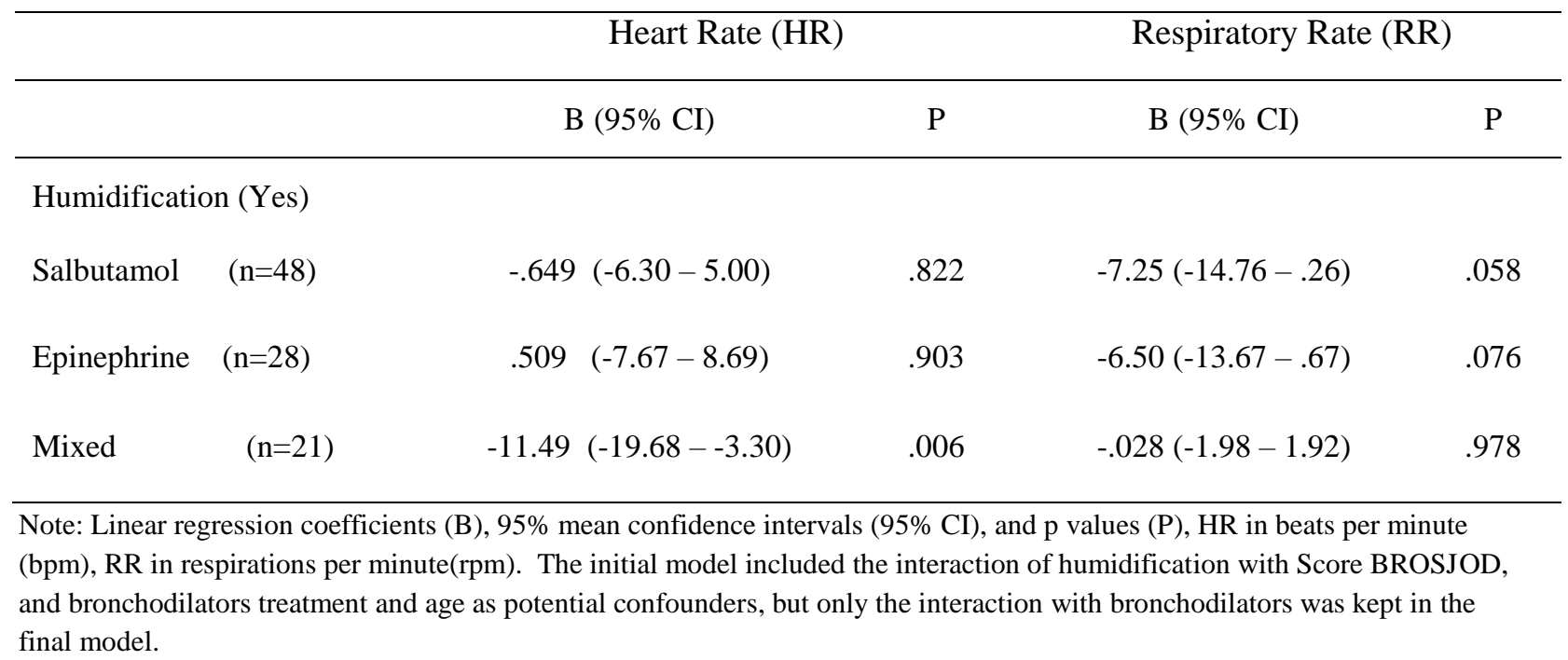


Table 6 Effects of humidification on length of stay and length of oxygen requirement across different bronchiolitis severity Score BROSJOD levels

Length of Stay $(\mathrm{LoS})$
Length of oxygen requirement (LOR)

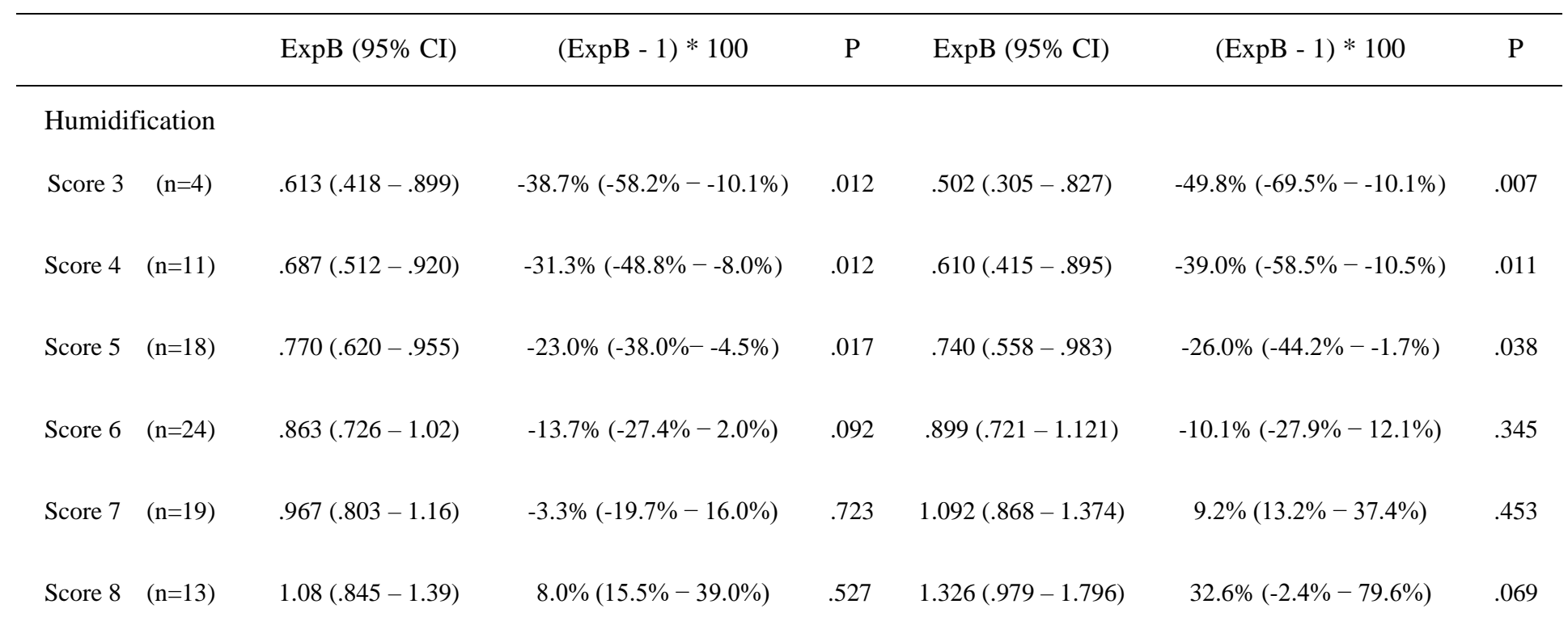

Note: Poisson regression coefficients $(\operatorname{Exp}(\mathrm{B})), 95 \%$ Confidence Intervals $(95 \% \mathrm{CI})$, and p values $(\mathrm{P})$. LoS and LOR in days.

$($ ExpB -1$) * 100$ shows the effect of humidification on length of stay and length of oxygen requirement expressed in percentage of change. The initial model included the interaction of humidification with Score BROSJOD, and admission weight, breastfeeding and age as potential confounders, but only the interaction with Score was kept in the final model. 